\title{
Green Synthesis of Reduced Graphene Nanosheets using Leaf Extract of Tridax procumbens and its Potential In Vitro Biological Activities
}

\author{
Nathiya Thiyagarajulu 1(D), Sivakumar Arumugam 2,*(D), Aranganathan Lakshmi Narayanan 3(D), \\ Tamilventhan Mathivanan ${ }^{4}$, Remya Rajan Renuka ${ }^{5}$ \\ 1 School of Bio-Sciences and Technology, Vellore Institute of Technology, Vellore 632 014, Tamil Nadu, India; \\ tnathiya.16@gmail.com (N.T.); \\ 2 School of Bio-Sciences and Technology, Vellore Institute of Technology, Vellore-632 014, Tamil Nadu, India; \\ siva_kumar.a@vit.ac.in (S.A.); \\ 3 Centre for Ocean Research (DST-FIST sponsored center), Sathyabama Institute of Science and Technology, Jeppiaar \\ Nagar, Rajiv Gandhi Salai, Chennai 600 119, Tamil Nadu, India; l.aranganathansai@gmail.com (A.L.); \\ 4 Adiuvo diagnostics Pvt. Ltd, Sipcot IT Park, Siruseri, Chennai 603 103, Tamil Nadu, India; tamil.vkk@ gmail.com (T.M.); \\ 5 Department of Biotechnology, Karapaga Vinayaga College of Engineering and Technology, Chengalpattu, Tamil Nadu \\ 603 308, India; remya.praveen5@gmail.com; \\ * Correspondence: siva_kumar.a@vit.ac.in;
}

Scopus Author ID 56404283300

Received: 12.07.2020; Revised: 15.09.2020; Accepted: 18.09.2020; Published: 24.09.2020

\begin{abstract}
Graphene oxide nanoparticles have found immense application in biotherapeutics owing to its biocompatibility and enhanced effectiveness in drug delivery. The present study investigates the green synthesis of reduced graphene oxide (rGO) using leaf extract using Tridax procumbens and testing its in-vitro biological activities. The biosynthesized TP-rGO was characterized by various spectroscopic and microscopic techniques. UV-vis spectroscopic primarily detected the absorption peak from 232 to $287 \mathrm{~nm}$. XRD spectra showed diffraction peak $2 \theta$ at $25^{\circ}$, confirming the presence of reduced GO. FTIR and Raman spectra confirmed effective deoxygenation of GO assisted by bioactive molecules present in the leaf extract. EDAX revealed the presence of carbon (74\%) and oxygen (24\%). TEM analysis revealed the presence of graphene nanosheets structure appearing as a thin sheet stacked with one another. The bioreduced rGO showed an antioxidant effect against DPPH radical observed in a concentration-dependent manner. The TP-rGO nanosheets were confirming the enhanced antibacterial effects against gram-positive pathogens than gram-negative bacteria. Hence, it is highlighted that leaf extract of $T$. procumbens act as a green, reducing agent for the successful biosynthesis of rGO nanosheets demonstrating potential in-vitro biological activities and has great scope in the preparation of nano drugs for the treatment of various diseases.
\end{abstract}

Keywords: Green synthesis; Tridax procumbens; reduced graphene oxide; antioxidant effect; antibacterial activity.

(C) 2020 by the authors. This article is an open-access article distributed under the terms and conditions of the Creative
Commons Attribution (CC BY) license (https://creativecommons.org/licenses/by/4.0/).

\section{Introduction}

Graphene and graphene oxide has been widely investigated as probably the most encouraging biomaterials for biomedical applications because of their particular properties: two-dimensional planar structure, huge surface region, substance, and mechanical constancy, radiant conductivity, and great biocompatibility [1,2]. These properties bring about promising applications for the progressive drug delivery vehicle and conveyance of a wide scope of 
therapeutics [3]. It is additionally utilized for biofunctionalization of protein, in anticancer treatment, as an antimicrobial operator for bone and teeth implantation [4].

The biocompatibility of the recently integrated nanomaterials permits its generous use in drug and science [5]. Aerosol pyrolysis [6], discharge arc [7], chemical reduction of graphene oxide by solution [8], deposition of chemical vapor [9], mechanical and thermal exfoliation of natural graphite synthesis [10] protocol are generally used for the synthesis rGO nanosheets. Among these protocols, industries are widely adopting the chemical method for rGO synthesis [11]. Highly harmful and toxic chemical solvents were used to synthesis GO to rGO [12]. These chemical reducing agents are hazardous for the environment [13]. Due to these reasons, industries are focusing on environment-friendly and sustainable reduction routes for the synthesis of bulk carbon materials using plant extract [14].

Nowadays, nanoparticles synthesizing from plants has gained more attention due to their biological activities such as anti-inflammatory, antibacterial, antifungal, antiviral, antiangiogenesis, antiplatelet, and anticancer activities [15,16]. Biosynthesis of Green nanoparticles reports being perfect, non-toxic, cost-effective, and environment-friendly [17]. Among the different biological techniques, industries are showing much interest in the green synthesis of nanoparticles from plant extract because of their simplicity of scale-up, less biohazardous nature [18]. In the previous decade, the synthesis of green nanoparticles becomes a significant part of nanotechnology due to its potential application in energy science, biomedical, attractive, and aerospace enterprises [19].

A lot of nanoparticles can be effectively incorporated from plants, and most of these are harmless to the environment [20]. Hence the present study is focusing on converting GO to rGO nanosheets using the medicinal plant Tridax procumbens. This species belongs to the Asteraceae family, native to South America, and mostly found in India in place of Maharashtra [21]. In ancient days, Tridax procumbens is generally used in ayurvedic treatment in India [22]. Tridax procumbens is widely used in the treatment of healing wounds, bone disorder, antidiabetic, anti-inflammatory, anticancer, antimalarial, hepatoprotective, etc., [23].

The modified hummer method was used to synthesize the reduced graphene oxide assisted by the leaf extract of Tridax procumbens. Then UV analysis, XRD, FTIR, Raman spectroscopy, EDAX, and TEM, characterization were carried out to confirm the synthesis of reduced graphene nanoparticles'. Further, the study also investigated their antioxidant, antibacterial activity of graphene nanoparticles synthesized from Tridax procumbens. So far, there is no report on the synthesis graphene nanoparticles by using the leaf extract of Tridax procumbens. The present investigation was intended to blend and describe graphene nanosheets.

\section{Materials and Methods}

\subsection{Synthesis of reduced graphene oxide ( $r G O)$ nanosheets.}

The slightly modified hummer method was used to prepare graphene oxide (GO) [24, 25]. For the synthesis of reduced graphene oxide ( $\mathrm{rGO}$ ), $10 \mathrm{mg}$ of dried Tridax procumbens leaf extract, and $40 \mathrm{mg}$ of GO was added in $100 \mathrm{ml}$ distilled water and sonicated for 30-40 mins. The yellowish-brown GO subsequent reaction solution was refluxed at $95^{\circ} \mathrm{C}$ in a water bath for $12 \mathrm{~h}$. After $12 \mathrm{~h}$, the yellowish-brown color of GO turn into black color confirmed the successful deoxygenation of graphene oxide. The obtained black color mixture was centrifuged 
at 10,000 rpm for $10 \mathrm{~min}$. The collected residues were washed with deionized water and then dried. The fine black powder of TP-rGO was stored in vials for further studies.

\subsection{Spectroscopic and morphological characterization.}

UV-visible spectra of GO and TP-rGO were obtained using a UV-visible spectrophotometer (JASCO, V670 UV-visible spectrophotometer). X-ray diffraction (XRD) analyses were carried out using an X-ray diffractometer (BRUCKERD8 advance diffractometer). FTIR spectra were recorded over in the wavelength range of $4000-400 \mathrm{~cm}^{-1}$ using $\mathrm{KBr}$ pellets (FT-IR SHIMADZU IR affinity-1S spectrophotometer). Raman spectroscopy (HORIBA Scientific Raman spectrophotometer) analysis was carried out to determine the $\mathrm{G}$ and $\mathrm{D}$ band. The presence of the elemental compound in TP-rGO was analyzed by Energy Dispersive X-Ray Analysis (EDAX) (ZEISS EVO18). Morphological analysis of the sample was performed using scanning electron microscopy (ZEISS EVO18) equipment and Transmission electron microscopy (FEI-TECNAI G2-20 TWIN).

\subsection{Invitro biological applications.}

2.3.1. Antioxidant assay.

The free radical scavenging effect of the GO and TP-rGO bioreduced GO was evaluated by the DPPH assay [26]. Different concentration of the GO and $\mathrm{rGO}(25 \mu \mathrm{g} / \mathrm{ml}, 50 \mu \mathrm{g} / \mathrm{ml}, 75$ $\mu \mathrm{g} / \mathrm{ml}$, and $100 \mu \mathrm{g} / \mathrm{ml}$ ) was mixed with $3 \mathrm{ml}$ of a methanol solution containing DPPH. The reaction mixture was shaken well and kept for $60 \mathrm{~min}$ in a dark place. The reduction of DPPH radicals was monitored using UV spectroscopy by measuring the absorption at $517 \mathrm{~nm}$. Ascorbic acid was used as a standard. The inhibition percentage (\%) of antioxidant activity was calculated using the formula, $\left[\left(\mathrm{A}_{0}-\mathrm{A}_{1}\right) / \mathrm{A}_{0}\right] \mathrm{x} 100$, where $\mathrm{A}_{0}$ is the absorbance of blank, and $\mathrm{A}_{1}$ is the absorbance of the sample.

\subsubsection{Antibacterial assay.}

The antibacterial effect of the GO and Tridax procumbens bioreduced rGO was demonstrated using Agar well diffusion method [27] against gram-positive (B.subtilis, S.epidermis) and gram-negative (E.coli, P.aeruginosa) bacterial pathogens. Different concentrations of the GO and $\mathrm{rGO}(25 \mu \mathrm{g} / \mathrm{ml}, 50 \mu \mathrm{g} / \mathrm{ml}, 75 \mu \mathrm{g} / \mathrm{ml}$, and $100 \mu \mathrm{g} / \mathrm{ml})$ were poured into the wells of Muller-Hinton agar plates, and the plates were incubated at $37^{\circ} \mathrm{C}$ for $24 \mathrm{~h}$. The inhibition zone was measured in $\mathrm{mm}$.

\section{Results and Discussion}

\subsection{Spectroscopic and morphological characterization.}

\subsubsection{UV Spectrophotometer.}

The reduced graphene oxide by Tridax procumbens was monitored by the UV-visible analysis. The characterization of the sample was extracted from a part of the reaction mixture in a regular interval, as shown in Fig 1, where the UV-vis range of the GO shows an absorption peak at $232 \mathrm{~nm}$, indicates that the peak may attribute to the $\pi-\pi$ transition of $\mathrm{C}-\mathrm{C}$ aromatic bonds. The TP-rGO absorption peaks state that the $\pi-\pi$ transition of $\mathrm{C}-\mathrm{C}$ aromatic bonds was shifted to $287 \mathrm{~nm}$. The high peak absorbance indicates that the Tridax procumbens has a good 
ability to reduce $\mathrm{GO}$ to $\mathrm{rGO}$ nanosheets. A different plant extract used for rGO synthesis, such as Eucalyptus [28], Annona squamosa [29], Lantana camara [30] showed a high absorbance peak than GO in UV-vis analysis.

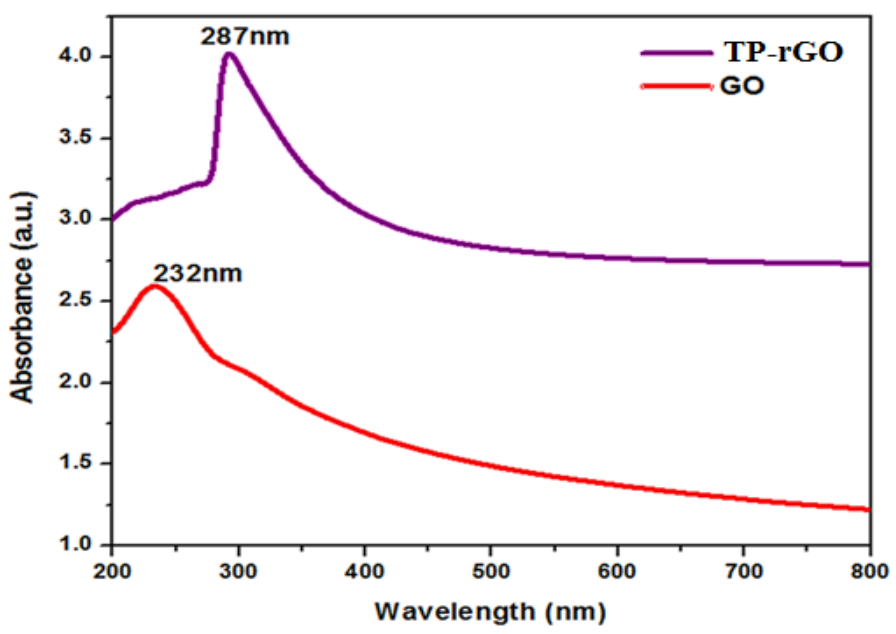

Figure 1. UV-Vis spectra of GO and TP-rGO nanosheets.

\subsubsection{XRD.}

XRD patterns of GO and TP-rGO are shown in Fig.2. The single XRD reflection peak of $\mathrm{GO}$ obtained at $2 \theta=10.6^{\circ}$ with a d-spacing interlayer corresponding of $0.83 \mathrm{~nm}$, which indicates the presence of carboxylic groups and water intercalation among the layers of graphite oxidation. In the XRD of the TP-rGO, GO peak was disappeared, and a new broad peak appeared at $2 \theta=25^{\circ}$ with a d-spacing interlayer corresponding to $0.36 \mathrm{~nm}$, indicates the reduction of GO. The less d-spacing value of rGO confirmed the absence of oxygen groups [31].

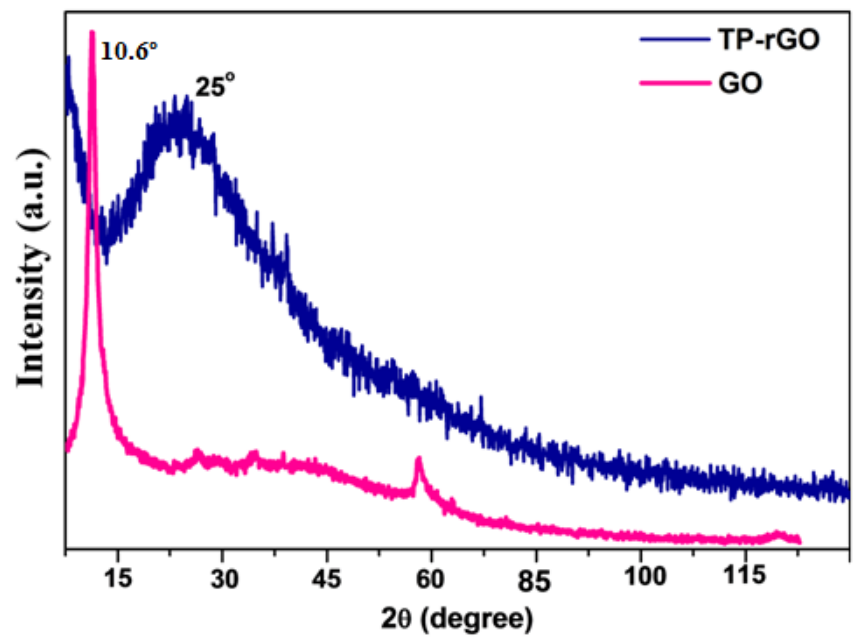

Figure 2. X-ray diffraction of GO and TP-rGO nanosheets.

\subsubsection{FTIR analysis.}

The TP-rGO was characterized by FT-IR to determine the structural changes that happened when deoxygenation. Fig. 3 shows the IR spectra of the GO and TP-rGO. Both GO, and TP-rGO FT-IR patterns showed a strong, broad peak at $3353 \mathrm{~cm}^{-1}$ and $3242 \mathrm{~cm}^{-1}$, which indicates the stretching vibrations of the hydroxyl groups [32]. The peak observed at $2927 \mathrm{~cm}^{-}$ ${ }^{1}$ represents the C-H group [33], which presence in TP-rGO but disappears in GO. The carbonyl 
group was present in GO at $1728 \mathrm{~cm}^{-1}$, but this band peak disappeared in TP-rGO due to the absence of carbonyl group, confirms that the GO reduction was successfully achieved [34]. $1613 \mathrm{~cm}^{-1}$ and $1623 \mathrm{~cm}^{-1}$ peak were observed in GO, and TP-rGO denotes the characteristic of the $\mathrm{C}=\mathrm{C}$ stretching bond [35]. The peak appears at $1368 \mathrm{~cm}^{-1}$ in $\mathrm{GO}$, and $1394 \mathrm{~cm}^{-1}$ in TP-rGO indicates C-O-H plane bending vibrations bond [36]. Furthermore, peaks observed at $1040 \mathrm{~cm}^{-}$ ${ }^{1}$ in GO, and $1058 \mathrm{~cm}^{-1}$ in TP-rGO represents the presence of C-O-C glycosidic linkages and C$\mathrm{O}$ stretching vibration of $\mathrm{C}-\mathrm{OH}$ bond [37]. These functional groups reveal that the $\mathrm{GO}$ reduction was successfully achieved by using Tridax procumbens leaf extract.

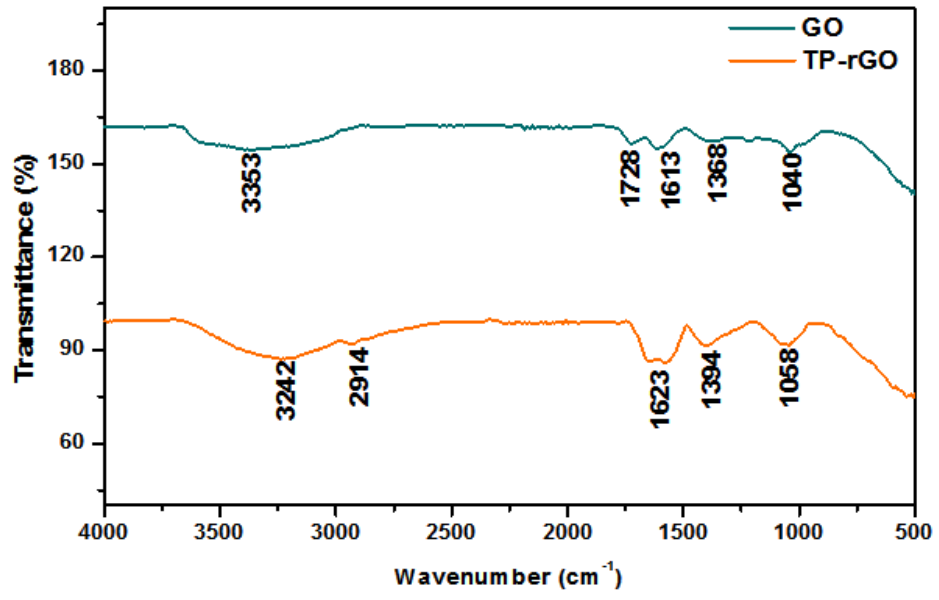

Figure 3. FTIR analysis of GO and TP-rGO nanosheets.

\subsubsection{Raman analysis.}

The Raman spectra of GO and TP-rGO is represented in Fig. 4. Generally, the spectra of graphene exhibit the presence of two peaks: G-peak arising from the first-order scattering of the E2 $\mathrm{g}$ phonon from $\mathrm{sp}^{2}$ carbon atoms $\left(1575 \mathrm{~cm}^{-1}\right)$ and D-peak $\left(1355 \mathrm{~cm}^{-1}\right)$ due to the breathing mode of $\kappa$-point photons of $\mathrm{A}_{1 \mathrm{~g}}$ symmetry [38].

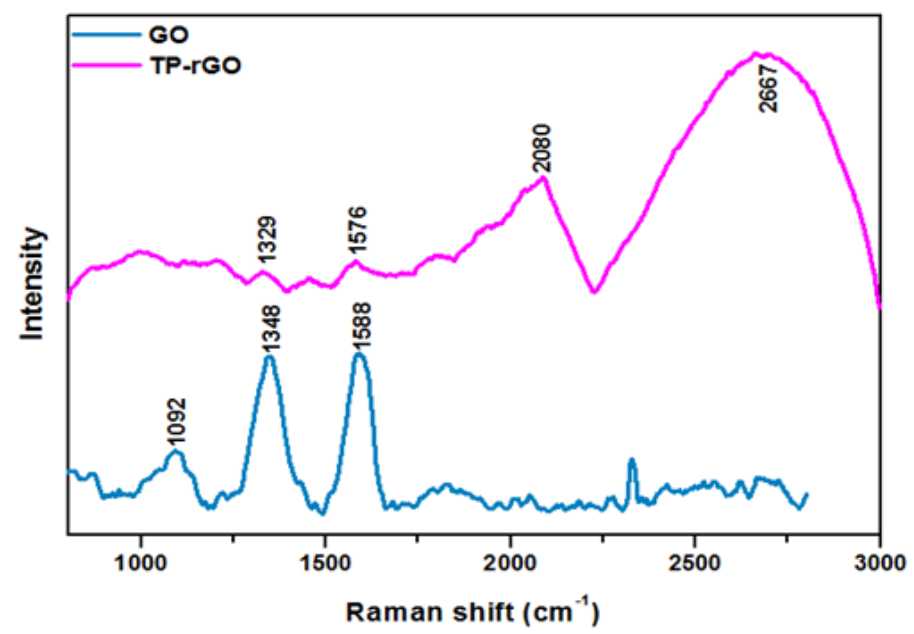

Figure 4. Raman analysis of GO and TP-rGO nanosheets.

The spectra of GO possess a D band at $1348 \mathrm{~cm}^{-1}$ and $\mathrm{G}$ band at $1588 \mathrm{~cm}^{-1}$. In the Raman spectrum of TP-rGO, both G and D bands were broadened and shifted to $1576 \mathrm{~cm}^{-1}$ and $1329 \mathrm{~cm}^{-1}$, which could be attributed due to graphitic self-healing and successful reduction, as removal of oxygen-containing functional groups promotes TP-rGO to associate and restack respectively [39]. The $\mathrm{ID}_{\mathrm{D}} \mathrm{I}_{\mathrm{G}}$ intensity ratio of GO was calculated to be 0.8 , which has increased 
in TP-rGO (1.0), which was in agreement with the ratio of GO and rGO bioreduced using tannin [40]. The higher intensity ratio of GO was attributed to the defects introduced into the GO during oxidation and ultrasonic exfoliation. In contrast, the highest intensity ratio observed in TP-rGO indicated disorder on the graphene sheets [28]. Also, the higher intensity ratio observed in reduced GO was due to the introduction of $\mathrm{sp} 3$ defects after functionalization and incomplete recovery of the structure of graphene [10].

\subsubsection{EDAX and TEM analysis.}

EDAX spectrum was taken to confirm the elemental composition of TP-rGO that shows strong signals of elemental $\mathrm{C}(74 \%)$ and O (24\%). This EDAX result of TP-rGO supported the existence of $\mathrm{C}$ and $\mathrm{O}$ based functional groups represented in Table 1. In addition, the shape of TP-rGO was analyzed using TEM, and the results were shown in Fig. 5. The image of TP-rGO is a non-uniform sheet-like structure, and the wrinkled shape of the edges has appeared as crumbled. The amorphous nature of TP-rGO was confirmed by the SAED pattern (Fig. 5d). This may be due to non-uniform rGO, which was stacked over one another [41].

Table 1. EDAX of TP-rGO nanosheets.

\begin{tabular}{c|c} 
Element & Atomic\% \\
\hline $\mathrm{C} \mathrm{K}$ & 74.02 \\
\hline $\mathrm{O} \mathrm{K}$ & 24.50 \\
\hline $\mathrm{Mg} \mathrm{K}$ & 0.22 \\
\hline $\mathrm{K} \mathrm{K}$ & 1.60 \\
\hline $\mathrm{Ca} \mathrm{K}$ & 0.09 \\
\hline Total & 100
\end{tabular}
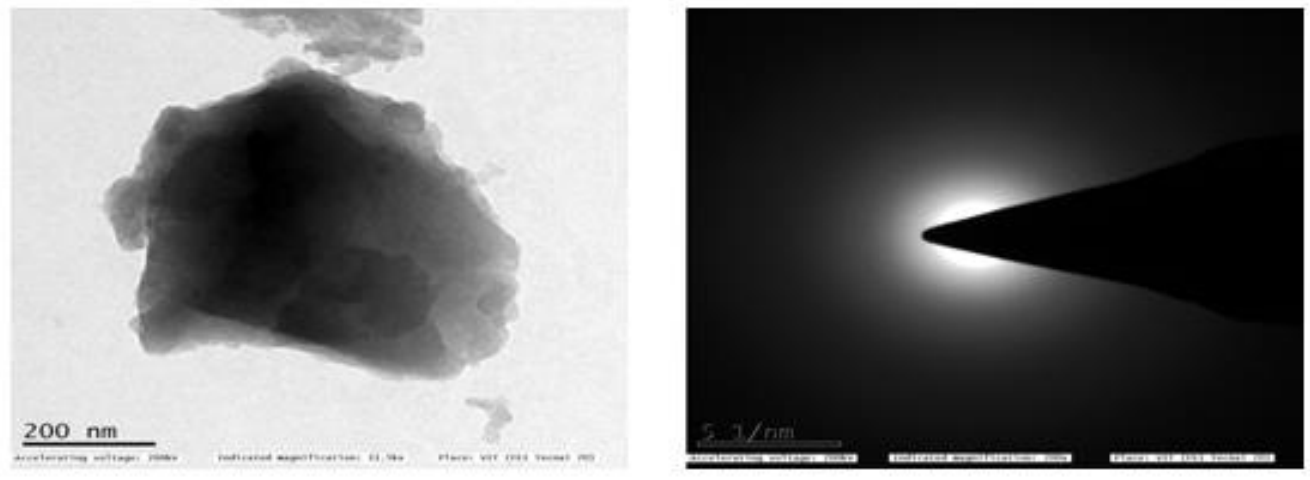

Figure 5. TEM image and SAED pattern of TP-rGO nanosheets.

\subsection{In-vitro biological applications.}

\subsubsection{Antioxidant assay.}

The antioxidant effect of GO and TP-rGO against DPPH free radical is represented in Fig. 6. The effect was observed in a dose-dependent manner. The maximum radical scavenging effect of GO (52\%) and TP-rGO (77\%) was achieved at $100 \mu \mathrm{g} / \mathrm{ml}$. The radical scavenging effect of the TP-rGO evaluated by DPPH assay showed potential radical scavenging effects. The properties of chemical functional moieties presence in TP-rGO may be one of the reasons for high radical scavenging activity. TP-rGO at high concentrations was able to release DPPH free radicals. Similar to our results, the study found that graphene materials may also have prooxidant activity and show ROS inhibition, and the antioxidant activity pattern can depend on the structure of graphene oxide [42]. 


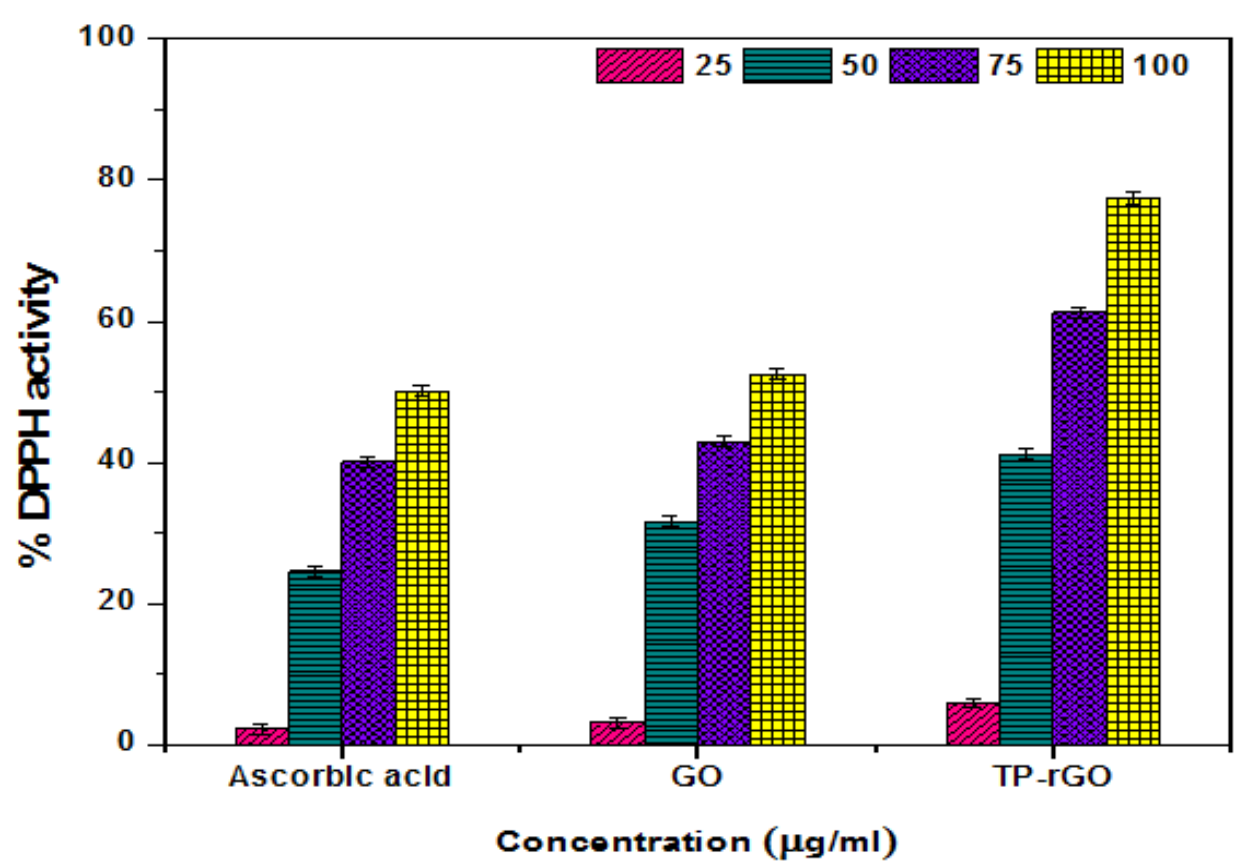

Figure 6. Antioxidant activity of GO and TP-rGO nanosheets.

\subsubsection{Antibacterial activity.}

The zone of inhibition is one of the effective methods to evaluate the antibacterial activity based on oxidation capacity. The comparative analysis of the bactericidal effects of GO and TP-rGO was measured by the zone of inhibition method, and results were represented in Fig. 7. In this experiment, both gram-positive (B.subitils and S.epidermidis) and gramnegative (E.coli and P.aeruginosa) were used. Among the gram-positive bacteria, more effective growth retardation was observed against B.subitils than S.epidermidis.The antibacterial effects of the rGO against the bacterial pathogens were observed to be in a dosedependent manner.
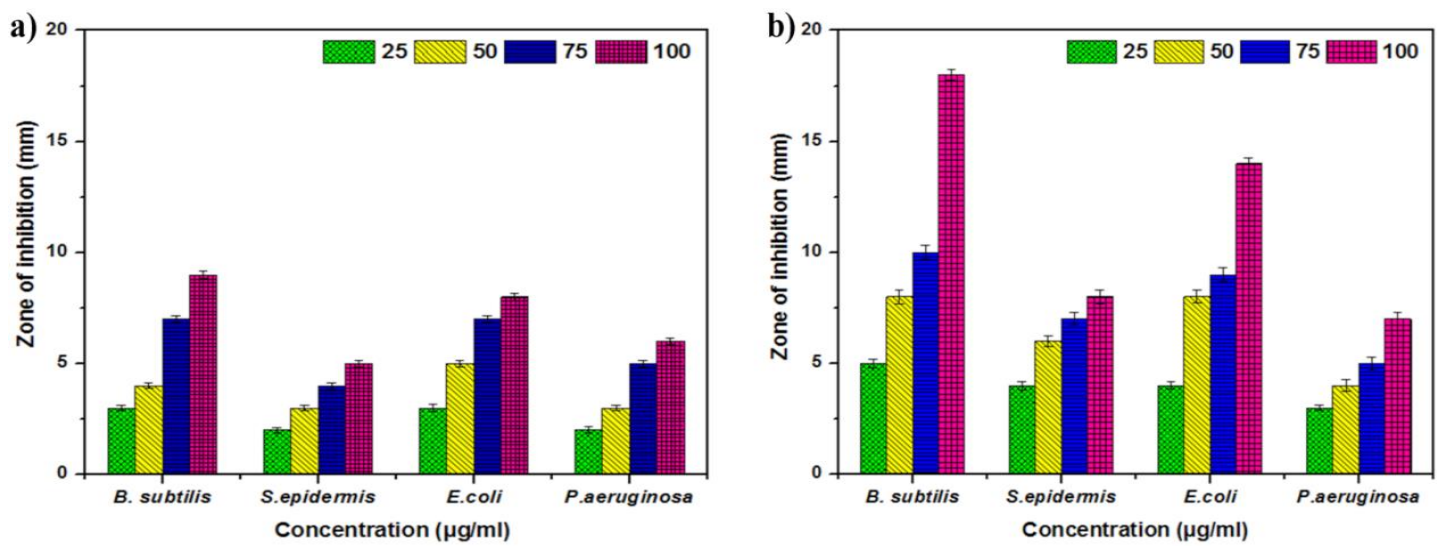

Figure 7. Antibacterial activity of (a) GO and (b) TP-rGO for various gram-positive and gram-negative bacteria.

The different dose concentrations of GO and TP-rGO, ranging from $25-100 \mu \mathrm{g} / \mathrm{ml}$, very slight variations in the measurement of inhibition zones were observed for both species (Fig.8). At high dose concentration $(100 \mu \mathrm{g} / \mathrm{ml})$, the inhibitory effectiveness was recorded high for B.subitils: $9 \mathrm{~mm}$ (GO), $18 \mathrm{~mm}$ (TP-rGO), S.epidermidis: $5 \mathrm{~mm}$ (GO), $9 \mathrm{~mm}$ (TP-rGO). In contrast, the bactericidal effect of GO and TP-rGO against gram-negative bacteria was also recorded effectively against E.coli $8 \mathrm{~mm}$ (GO), $14 \mathrm{~mm}$ (TP-rGO) than P.aeruginosa $6 \mathrm{~mm}$ (GO), $7 \mathrm{~mm}$ (TP-rGO). The bactericidal effect of TP-rGO was comparably more effective than 
GO against the bacterial isolates tested in different concentrations. Among the gram-negative bacteria tested, E.coli showed more susceptibility than P.aeruginosa. It is evident that the antibacterial activity of graphene-based materials may be influenced by two important material characteristics: size and oxidation capacity. Samples with a smaller size, higher oxidation capacity, and distortion in structural integrity by forming a gap within the membrane possess a higher antibacterial activity [23,43]. Overall, these results illustrated that TP-rGO showed better antibacterial activity compared to GO for both gram-positive and negative bacteria.
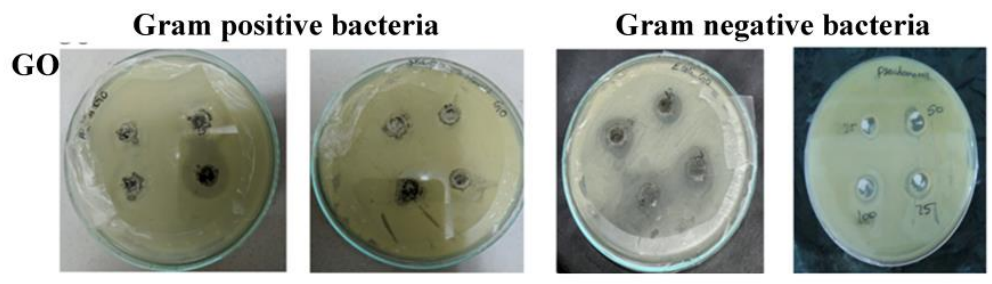

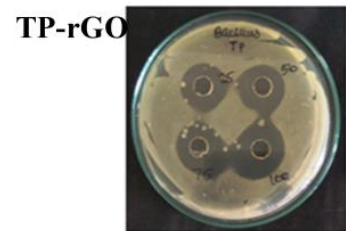

B.subtilis

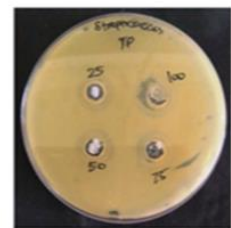

S.epidermis

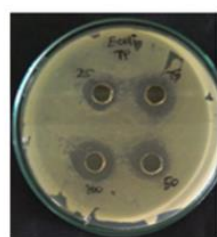

E.coli

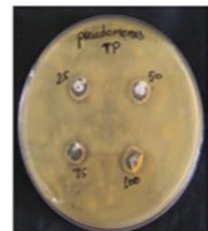

P.aeruginosa

Figure 8. Zone of inhibition Image of GO and TP-rGO nanosheets.

\section{Conclusions}

In this research, we successfully validated the reducing properties of Tridax procumbens leaf extract for reduced graphene oxide synthesis. UV, XRD, FTIR, Raman, and EDAX results confirmed the oxygen removal from the surface of GO. The layered nanosheet, like structures with some defects, was noticed through TEM results. The DPPH results assured the good antioxidant properties due to the synergism of phytochemicals present in Tridax procumbens leaf extract. The in-vitro antibacterial activity results showed that TP-rGO exhibited better biological properties against both gram-positive and negative bacteria. Biosynthesized TP-rGO is cost-effective, green, and eco-friendly. In this regard, the green nanomaterial, TP-rGO highlighted its promising potential to be used in biomedical applications.

\section{Funding}

This research received no external funding.

\section{Acknowledgments}

The authors gratefully thank Dr. K. Sathiyanarayanan, Professor, Department of Chemistry, Vellore Institute of Technology (VIT), Vellore, for support on this work and instrumentation facilities.

\section{Conflicts of Interest}

The authors declare no conflict of interest. 


\section{References}

1. Celina Selvakumari, J.; Nishanthi, S.T.; Dhanalakshmi, J.; Ahila, M.; Padiyan, D.P. Synthesis of graphene nanosheets using Camellia sinensis and its electrochemical behavior for energy storage application. Matererial Chemistry and Physics 2020, 239, https://doi.org/10.1016/j.matchemphys.2019.122001.

2. Kokkarachedu,V.; Matias, L.; Dariela, N.; Tippabattini, J.E.R.S.; Chandrasekaran, K.P.O. Antibiotic copper oxide-curcumin nanomaterials for antibacterial applications. JournalofMolecular Liquids2020, 300,https://doi.org/10.1016/j.molliq.2019.112353.

3. Liao, K.; Lin, Y.; Macosko, C.W.; Haynes, C.L. Cytotoxicity of Graphene Oxide and Graphene in Human Erythrocytes and Skin Fibroblasts. Applied Materials and Interfaces 2011,3, 2607-2615, https://doi.org/10.1021/am200428v.

4. Moones, H,; Morteza, G.A.N. Green synthesis of SnO2-bentonite nanocomposites for the efficient photodegradation of methylene blue and eriochrome black-T. Materials Chemistryand Physics 2019, 24, https://doi.org/10.1016/j.matchemphys.2019.122416.

5. Al-ani, L.A.; Yehye, W.A.; Kadir, F.A.; Najihah, M.H.; Mohammed, A.A.; Nurhidayatullaili, M.J.; Vincent, K.S.H. Hybrid nanocomposite curcumin-capped gold nanoparticle-reduced graphene oxide : Anti- oxidant potency and selective cancer cytotoxicity. PLoS One2019, 50, 1-24, https://doi.org/10.1371/journal.pone.0216725.

6. Campos-delgado, J.; Romo-herrera, M.; Jia, X.; David, A.C.; Hiroyuki, M.; Yoong, A.; Takuya, H.; Zhifeng, R.; David, J.S.; Yu, O.;Tomonori, O.; Hirofumi, K.; Katsumi, K.; Morinobu, E.; Humberto, T.; Mildred S. D.; Mauricio, T. Bulk Production of a New Form of sp 2 Carbon : Crystalline Graphene Nanoribbons. Nano Letters2008, 8, 2773-2778, https://doi.org/10.1021/nl801316d.

7. Subrahmanyam, K.S.; Panchakarla, L.S.; Govindaraj, A.; Rao, C.N.R. Simple Method of Preparing Graphene Flakes by an Arc-Discharge Method. Journal of Physical Chemistry letters 2009, 113, 4257-4259, https://doi.org/10.1021/jp900791y.

8. Chua, C.K.; Pumera, M. Chemical reduction of graphene oxide : a synthetic chemistry viewpoint. Chemical Society Reviews 2014, 43, 291-312, https://doi.org/10.1039/c3cs60303b.

9. Mattevi, C.; Hokwon, K.; Chhowalla, M. A review of chemical vapour deposition of graphene on copper. Journal of Material Chemistry2011, 21, 3324-3334, https://doi.org/10.1039/c0jm02126a.

10. Mcallister, M.J.; Li, J; Douglas, H.A.; Hannes, C.S.; Ahmed, A.A.; Jun, L.X.O.; Margarita, H.A.; David, L.M.; Roberto, C.; Robert, K. P.; Ilhan, A.A.; Li, J. Single Sheet Functionalized Graphene by Oxidation and Thermal Expansion of Graphite. Chemical Materials2007,19, 4396-4404, https://doi.org/10.1021/cm0630800.

11. Amaro-gahete, J.; Ben, A.; Esquivel, D.A. Comparative Study of Particle Size Distribution of Graphene Nanosheets Synthesized by an Ultrasound-Assisted Method. Nanomaterials2019, 9, https://doi.org/10.3390/nano9020152.

12. Dreyer, D.R.; Park, S.; Bielawski, W.; Ruoff, R.S. The chemistry of graphene oxide. Chemical Society Reviews 2010, 39, 228-240, https://doi.org/10.1039/b917103g.

13. Singh, C.; Ali,A.; Sumana, G. Green Synthesis of Graphene Based Biomaterial using Fenugreek Seeds for Lipid Detection Green Synthesis of Graphene Based Biomaterial using Fenugreek Seeds for Lipid Detection. ACS Sustainable Chemistry Engineering2016,4,https://doi.org/10.1021/acssuschemeng.5b00923.

14. Bandeira, M.; Giovanela, M.; Roesch, E.M.; Devine, D.M.; Silva, C.J. Green synthesis of zinc oxide nanoparticles: A review of the synthesis methodology and mechanism of formation. Sustainable Chemistry and Pharmacy2020,15,https://doi.org/10.1016/j.scp.2020.100223.

15. Suman, T.Y.; Radhika Rajasree S.R.; Ramkumar, R.; Rajthilak, C.; Perumal, P. The Green synthesis of gold nanoparticles using an aqueous root extract of Morinda citrifolia L. Spectrochim Acta - Part A Mol Biomol Spectrosc2014,118,11-16, https://doi.org/10.1016/j.saa.2013.08.066.

16. Aarti, P.; Nikam, M. P.; Ratnaparkhi, S.P.C. Nanoparticles: An Overview. Journal of Drug Deliv Ther2014,3, 1121-1127, https://doi.org/10.22270/jddt.v3i2.407.

17. Bakhshali-Dehkordi, R.; Ghasemzadeh, M.A.; Safaei-Ghomi, J. Green synthesis and immobilization of TiO2 NPs using ILs-based on imidazole and investigation of its catalytic activity for the efficient synthesis of pyrimido[4,5-d]pyrimidines. Journal of Molecular Structure 2020, 1206, https://doi.org/10.1016/j.molstruc.2020.127698.

18. Shah, M.; Fawcett, D.; Sharma, S.; Tripathy, S.K.; Poinern, G.E. Green Synthesis of Metallic Nanoparticles via Biological Entities. Materials 2015, 8, 7278-7308, https://doi.org/10.3390/ma8115377.

19. Bakht, M.A. Eco-friendly synthesis of isatin-thiazolidine hybrid using graphene oxide catalyst in deep eutectic solvent and further evaluated for antibacterial, anticancer and cytotoxic agents. Sustainable Chemistry and Pharmacy 2020, 16,https://doi.org/10.1016/j.scp.2020.100252.

20. Lingaraju, K.; Raja Naika, H.; Nagaraju, G.; Nagabhushana, H. Biocompatible synthesis of reduced graphene oxide from Euphorbia heterophylla (L.) and their in-vitro cytotoxicity against human cancer cell lines. Biotechnology Reports 2019, 24,https://doi.org/10.1016/j.btre.2019.e00376.

21. Agrawal, S.; Mohale, D.; Talele, G.S. Pharmacological activities of Tridax procumbens ( Asteraceae). Medicinal plants 2010, 2, 73-78. 
22. Beck, S.; Mathison, H.; Todorov ,T.; Calderó, E. A Review of Medicinal Uses and Pharmacological Activities of Tridax Procumbens (L.). Journal of Plant studies2018,7,19-35, https://doi.org/10.5539/jps.v7n1p19.

23. Rani, R.; Sharma, D.; Chaturvedi, M.; Yadav, J.P. Green synthesis of silver nanoparticles using Tridax procumbens: their characterization, antioxidant and antibacterial activity against MDR and reference bacterial strains. Chemical Papers 2020, 74, 1817-1830, https://doi.org/10.1007/s11696-019-01028-w.

24. Thakur ,S.; Karak, N. Green reduction of graphene oxide by aqueous phytoextracts. Carbon 2012, 50, ,53315339, https://doi.org/10.1016/j.carbon.2012.07.023.

25. Hummers, W.S.; Offeman, R.E. Preparation of Graphitic Oxide. Journal of the American Chemical Society 1958, 80, 1339-1339,https://doi.org/10.1021/ja01539a017.

26. Adhikari, B.; Dhungana, S.K.; Waqas Ali, M.; Adhikari, A.; Kim, I.-D.; Shin, D.-H. Antioxidant activities, polyphenol, flavonoid, and amino acid contents in peanut shell. Journal of the Saudi Society of Agricultural Sciences 2019, 18, 437-442,https://doi.org/10.1016/j.jssas.2018.02.004.

27. Mahendran, R.; Sridharan, D.; Santhakumar, K.; Selvakumar, T.A.; Rajasekar, P.; Jang, J.H. Graphene Oxide Reinforced Polycarbonate Nanocomposite Films with Antibacterial Properties. Indian Journal of Materials Science 2016, 2016, 1-10, https://dx.doi.org/10.1155/2016/4169409.

28. Li, C.; Zhuang, Z.; Jin, X.; Chen, Z. A facile and green preparation of reduced graphene oxide using Eucalyptus leaf extract. Applied Surface Science 2017, 422, 469-474, https://doi.org/10.1016/j.apsusc.2017.06.032.

29. Chandu, B.; Mosali, V.S.S.; Mullamur, I.B.; Bollikolla, H.B. A facile green reduction of graphene oxide using annona squamosa leaf extract. Carbon Letters2017, 21, 74-80, https://doi.org/10.5714/CL.2017.21.074.

30. Thiyagarajulu, N.; Arumugam, S. Green Synthesis of Reduced Graphene oxide Nanosheets Using Leaf Extract of Lantana camara and Its In-Vitro Biological Activities. Journal of Cluster Science 2020, 7, 0181401817, https://doi.org/10.1007/s10876-020-01814-7.

31. Zaaba, N.I.; Foo, K.L.; Hashim, U.; Tan, S.J.; Liu, W.-W.; Voon, C.H. Synthesis of Graphene Oxide using Modified Hummers Method: Solvent Influence. Procedia Engineering 2017, 184, 469-477, https://doi.org/10.1016/j.proeng.2017.04.118.

32. Alam, S.N.; Sharma, N.; Kumar, L. Synthesis of Graphene Oxide (GO) by Modified Hummers Method and Its Thermal Reduction to Obtain Reduced Graphene Oxide (rGO). Graphene2017,06,1-18, https://doi.org/10.4236/graphene.2017.61001.

33. Moosa, A.A.; Jaafar, J.N. Green Reduction of Graphene Oxide Using Tea Leaves Extract with Applications to Lead Ions Removal from Water. Nanoscience and Nanotechnology2017, 7, 38-47.

34. Firdhouse, M.J.; Lalitha, P. Phyto-reduction of graphene oxide using the aqueous extract of Eichhornia crassipes (Mart.) Solms. International Nano Letters 2014, 4, 103-108,https://doi.org/10.1007/s40089-0140125-4.

35. Mahata, S.; Sahu, A.; Shukla, P.; Rai, A.; Singh, M.; Rai, V.K. The novel and efficient reduction of graphene oxide using Ocimum sanctum L. leaf extract as an alternative renewable bio-resource. New Journal of Chemistry 2018, 42, 19945-19952,https://doi.org/10.1039/c8nj04086a.

36. Fathy, M.; Mohamed, R.H.; Amany, K. Green synthesis of graphene oxide from oil palm leaves as novel adsorbent for removal of $\mathrm{Cu}$ ( II ) ions from synthetic wastewater. Graphene Technology2019, 4, 33-40, https://doi.org/10.1007/s41127-019-00025-w.

37. Hidayah, N.M.S.; Liu, W.-W.; Lai, C.-W.; Noriman, N.Z.; Khe, C.-S.; Hashim, U.; Lee, H.C.; Aziz, H.A.; Bakar, B.H.A.; Johari, M.A.M.; Keong, C.K.; Yusoff, M.S.; Hasan, M.R.M.; Ramli, M.H.; Halim, H. Comparison on graphite, graphene oxide and reduced graphene oxide: Synthesis and characterization. AIP Conference Proceedings 2017, 1892, 150002-150008, https://doi.org/10.1063/1.5005764.

38. Gurunathan, S.; Han, J.W.; Eppakayala, V.; Dayem, A.A.; Kwon, D.-N.; Kim, J.-H. Biocompatibility effects of biologically synthesized graphene in primary mouse embryonic fibroblast cells. Nanoscale Research Letters 2013, 8,http://doi.org/10.1186/1556-276X-8-393.

39. Kudin, K.N.; Ozbas, B.; Schniepp, H.C.; Prud'homme, R.K.; Aksay, I.A.; Car, R. Raman Spectra of Graphite Oxide and Functionalized Graphene Sheets. Nano Letters 2008, 8, 36-41, https://doi.org/10.1021/n1071822y.

40. Lei, Y.; Tang, Z.; Liao, R.; Guo, B. Hydrolysable tannin as environmentally friendly reducer and stabilizer for graphene oxide. Green Chemistry 2011, 13, 1655-1658, http://doi.org/10.1039/c1gc15081b.

41. Lee, G.; Kim, B.S. Biological reduction of graphene oxide using plant leaf extracts. Biotechnology Progress 2014, 30, 463-469,https://doi.org/10.1002/btpr.1862.

42. Qiu, J.; Chen, L.; Zhu, Q.; Wang, D.; Wang, W.; Sun, X.; Liu, X.; Du, F. Screening natural antioxidants in peanut shell using DPPH-HPLC-DAD-TOF/MS methods. Food Chemistry 2012, 135, 23662371,https://doi.org/10.1016/j.foodchem.2012.07.042.

43. Krishnamoorthy, K.; Umasuthan, N.; Mohan, R.; Lee, J.; Kim, S.-J. Antibacterial Activity of Graphene Oxide Nanosheets. Science of Advanced Materials 2012, 4, 1111-1117, https://doi.org/10.1166/sam.2012.1402. 